\title{
Load Assessment/Evaluation of a Three Phase Four Wire Distribution System of a Technical Institution. A Case Study of Kumasi Polytechnic, Ghana.
}

\author{
Kwadwo Ntiamoah-Sarpong ${ }^{1}$, Kwame Sarfo ${ }^{2}$, Johannex Fefeh. Rushman ${ }^{3}$, Achiaa Donkor ${ }^{4}$

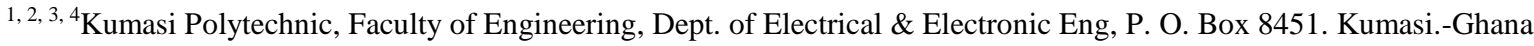

\begin{abstract}
A power system is subjected to numerous interruptions such as stresses, extension, and aging of system components, which degrade the power system and add harmonic properties to the system which eventually compromise the reliability and stability of the power system. The degradation is primarily of unmonitored changes which have been added to the system. Evaluation of these changes in the system helps in resolving load imbalances which lead to high current unbalances. High current unbalance is a measure of the health of a wye distribution system. Electric load monitoring generates important data that can help to unravel the mystery behind premise usage characteristics in commercial and industrial facilities. The high unbalanced phases in the institution distribution system, has resulted in high values of neutral currents in the system. The average value of neutral current within each cluster is very high. Increase in neutral currents leads to increase in $I^{2} R$ losses, and a decrease in the transformer efficiency. Unbalanced phases can lead intermittent failure of breakers and to fire outbreaks. .Percentage current Unbalance in each cluster has highly exceeded $10 \%$ of acceptable limit. Some loads need to be powered from appropriate phase to ensure balancing.
\end{abstract}

Keywords: Load assessment, phase current, current unbalance, efficiency, health status

\section{Introduction}

A power system is subjected to numerous interruptions such as stresses, extension, and aging of system components, which degrade the power system and add harmonic properties [1],[2] to the system which eventually compromise the reliability and stability of the power system. The degradation is primarily of unmonitored changes which have been added to the system. Evaluation of these changes in the system helps in resolving load imbalances which lead to high current unbalances. High current unbalance is a measure of the poor health of a three phase four wire distribution system. Electric load monitoring generates important data that can help to unravel the mystery behind premise usage characteristics in commercial and industrial facilities. Monitoring and evaluation is the systematic collection and analysis of information as a projected plan progresses or continues. Monitoring is very paramount in modern engineering system parameter which can be under study. Load monitoring is the collection of quality and harmonics data of a power system. Load monitoring service ensures that a facility power system is meeting the electrical demand of the electrical equipment and component feeding off from the power system. The Electricity supply and distribution (Technical and Operational) Rules of Ghana, LI (1816) of 2005, Rule 13 [3], recommends guidelines for customers of the Electricity supply and distribution companies in Ghana to ensure first and foremost that the customers electrical installation is safe for the supply of electricity . It includes among others under Quality of Supply of Electricity, harmonics control, negative sequence voltage, load balance and voltage fluctuations. These rules and guidelines make it convenient for the companies saddled with the responsibility of maintaining and operating the electricity generation and distribution system to keep their systems running smoothly, and at an economical price.
Kumasi Polytechnic is a modern technical institution located at the heart of the Garden City of West Africa, Kumasi the capital city of the Ashanti region of Ghana. The Polytechnic is currently organized into 6 Faculties, 2 institutes and 1 graduate school. The school can boast of well-equipped computer laboratories and other laboratories such as the CNC Lab, Industrial Electronics Lab, Mechatronics, Motor control and Power distribution Labs, Creative Arts and Textile Labs among others. These types of modern laboratories, demands high quality power. At the beginning of the 2014/15 academic year the total number of students enrolled stood at 9214, with 6222 being male and 2992 female. The Polytechnic is supplied with electricity from the Electricity Company of Ghana (ECG). The electrical power system of Kumasi Polytechnic has two (2) substations of capacities 315 KVA and 500KVA which distribute power to all parts of the school. The 500KVA also provides supply to some portions of the surrounding community outside the school. The continuous addition of electrical equipment as a result of the continuing expansion of the facilities on the campus results in the increase of the load on the power system. It is therefore necessary and important to monitor the complex experiences which the power system of the institution might be experiencing, and adopt appropriate measures to ensure a continuous and stable power supply system.

\section{Objective of Study}

The main objective is to measure and analyse the various parameters that provides an indication of the "health status" of the electrical distribution system of the Polytechnic.

The specific objectives are;

1)To know the load existing on the two substations at the Polytechnic. 


\section{International Journal of Science and Research (IJSR) \\ ISSN (Online): 2319-7064}

Index Copernicus Value (2013): 6.14 | Impact Factor (2015): 6.391

2)To determine the current load demand and to compare with the two existing transformers ratings.

\section{Relevance of the Study}

Changes in loads on power systems occur over time with increase in infrastructural development and can result in the gradual overloading of the system. Adding on of new equipment, increasing output or component changes can all have an effect on the load demands of a power system. Unmonitored these changes can cause the gradual degradation of the power system. The data was collected during the mid-day, determined to be the peak period. The distribution side to the surrounding communities was not considered in this research.

Load monitoring on an electrical distribution system is carried out to establish the consumption rate and efficiency of the distribution system. The power factor $(\operatorname{Cos} \Phi)$, real power $(\mathrm{KW})$, apparent power (KVAr), current (I), voltage (V) and harmonic distortion which contribute to power dissipation are all leading factors of higher power consumption rate.

There are several ways in which load can be monitored in a facility. The multi-meter is one of the most widely used instruments for measuring electrical parameters in industry [6]. The clamp-on multi-meter measures current and Probes measure voltage. Having a hinged "clamp" jaw integrated into an electrical meter allows users to simply clamp around wire, cables and other conductors at any point in the electrical system and measure its current, without disconnecting it form the source. The main principle of a clamp-on multi-meter is based on Faraday's law of electromagnetic induction.

The other medium in power disaggregation includes Intrusive Load Monitoring (ILM) and Non-intrusive Load Monitoring (NILM). The NILM approach is a process for detecting changes in the voltage and current existing in a house or facility and deducing appliance consumption in the facilities. Different approaches for NILM systems have been developed over the past few decades. Electric meters with NILM technology are used by utility companies to survey the specific uses of electric power in different homes. It is considered to be one of the low cost alternatives to attach to a premise or to an appliance, although it does present some level of privacy concerns [9].

The ILM approach requires more than one sensing meter to do the monitoring although the intrusive load monitoring method is more accurate in measuring energy consumption. This makes it more suitable for appliance load monitoring (ALM). The implementation of this ILM was based on development of the NALM. A number of initial tests were carried out on a facility loads to compare the NALM to traditional load monitoring techniques employed by electric companies [8].

Energy consumers have a wide variety of considerations and concerns where energy usage is involved. [3]This is largely due to the diversity of load types and requirements, energy consumption schedules, and the facility's level of toleration for a less-than-ideal energy source. In general, there are four basic categories of consumers: domestic, commercial, industrial, and governmental institutions. While each has a different objective for energy consumption and different expectations from its energy provider, many shared aims exist. Energy cost and the reliability of the electrical system are major concerns for most energy consumers. Different rate structures exist, depending on the category of consumer. Basic domestic consumers generally incur a flat or tiered billing structure rate that corresponds to their energy usage. More complex loads, such as industrial and commercial consumers, incur more complex rate structures that typically include some variation of power demand and energy usage. Clearly, power monitoring systems become more beneficial for heavier consumers.

Monitoring systems are also very useful for consumers that have a low tolerance for electrical perturbations, such as semiconductor fabrication or pharmaceutical industries. In these cases, the consumer's need for a reliable power source may outweigh their energy cost considerations because of the expenses associated with equipment downtime (e.g., loss of product, equipment, etc.). For this category of consumer, monitoring systems are used to quickly identify and resolve problems occurring on their electrical system.

Because power monitoring systems are "permanently installed," they operate on a continuity basis. Continuous logging of energy-related data provides information on the operational characteristics of an electrical system. Because the quality of energy supplied to a facility can adversely affect its operation, often times leading to loss or degradation of equipment, product, revenue, and reputation, plant managers must weigh the advantages of implementing a power monitoring program.

These information include; Where it's being consumed, When it's is being consumed, How is being consumed, what loads are consuming the energy? The information obtained helps in decision making leading to reduction in the energy delivered to and consumed by the electrical system.

\section{The Importance of Load Monitoring and Evaluation}

The longer the power system is going unmonitored the greater the potential exists for it to be subjected to degradation associated with higher harmonic. Load monitoring provides a better voltage quality as indicated on transformers for protection performance. Enhancing system reliability and power quality is also better advantage for monitoring loads. Monitoring pose immediate verification of power system changes and solutions by reliable data collected. In addition to its advantages, the enhancing of online predictive maintenance is a plus and helps in decision on load balancing. In load monitoring making projection for injection and upgrading is good and helps in lowering of cost.

\section{Methodology}

Volume 5 Issue 6, June 2016 www.ijsr.net

Licensed Under Creative Commons Attribution CC BY 


\section{International Journal of Science and Research (IJSR) \\ ISSN (Online): 2319-7064}

Index Copernicus Value (2013): 6.14 $\mid$ Impact Factor (2015): 6.391

Load calculation was performed on the Kumasi Polytechnic Electrical distribution system at various test points on campus for all sections of the school, grouped into clusters. Three different measurements were taken on 3 different days between 11.00am to 2.30pm o'clock, during the month of March and April 2016 for the whole institution. This period was chosen because it fell within the peak load period for the utility company. The Location, Maximum current $\left(\mathrm{I}_{\max }\right)$, phase voltage $\left(\mathrm{V}_{\mathrm{P}}\right)$, and power factor $(\cos \phi)$ were each measured for each of the load points (Cluster) and recorded for each day of the test. Further calculations were performed on the test results to determine the maximum power and load in (KVA), for each location. The total load (KVA) for the school was then determined. This was to enable the determination of the required total Plant capacity for the institution. The average of the total load was then computed from the three readings.

The approach used is as outlined below,

- Determine the distribution points by grouping the various sections in the institution into clusters

- Consider the two main transformers at the polytechnic by their ratings so as to compare with the current load demand.

- Tabulate and analyze each cluster by it load center panel rating as compared to existing load on it. Measure and record the Phase current (I phase), neutral current $\left(\mathrm{I}_{\mathrm{N}}\right)$ ,phase voltage (V phase), power factor $(\cos \phi)$,

Calculations are then performed according to the formals below [4], [5].

- Maximum current $\left(\mathrm{I}_{\mathrm{MAX}}\right)=\mathrm{L} 1+\mathrm{L} 2+\mathrm{L} 3$

- Phase voltage $\left(\mathrm{V}_{\mathrm{P}}\right)=\frac{415}{\sqrt{3}}=240$

- Maximum power $\left(\mathrm{P}_{\mathrm{MAX}}\right)=\mathrm{I}_{\mathrm{MAX}} \times \mathrm{V}_{\mathrm{p}} \times \operatorname{Cos} \varnothing$

Maximum power supplied in KVA =

Maximum Power Consumed $\operatorname{Cos} \emptyset$

- Total percentage load on transformer =

$$
\frac{\sum \text { legs }}{\text { transformer rating }} \times 100 \%
$$

$\sum$ oflegs $=$ total sun of legs on transformer $\div 3$

Percentage Current Unbalance $=$

$\left(\frac{\text { Maxicurrent dif fenence from averagecurrent }}{\text { average curnent }}\right) \times 100 \%$

$$
\text { Eg. average current }=L \text { av }=\left(\frac{L 1+L 2+L a}{a}\right)
$$

Max deviation from average current $=\mid(L N-$ Lav) l, where $N=$ Line $1,2,3$

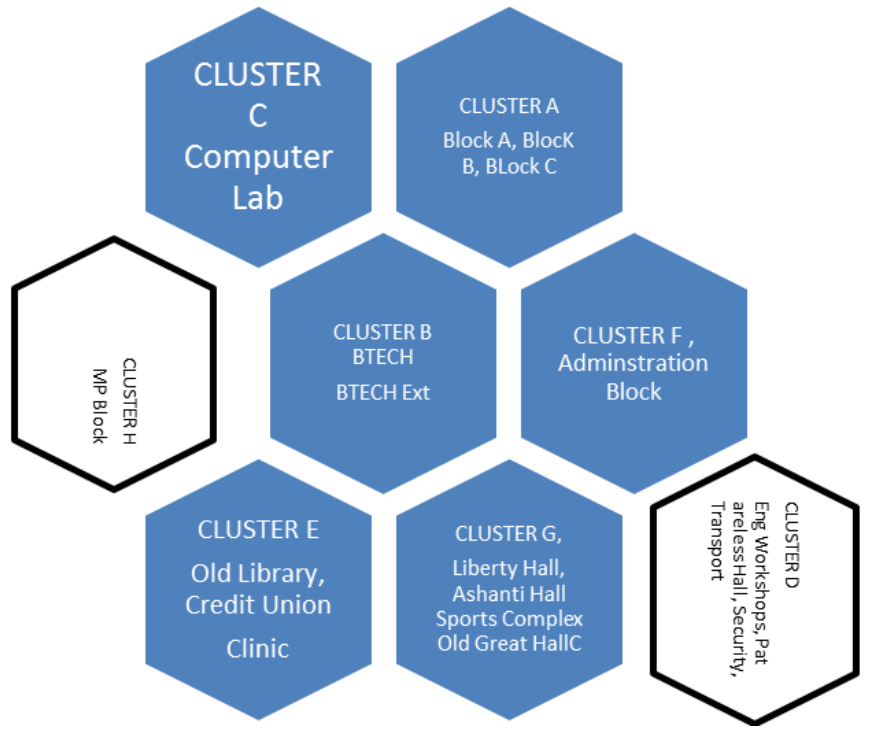

Figure 1: Chart Of Clusters under study and their respective components

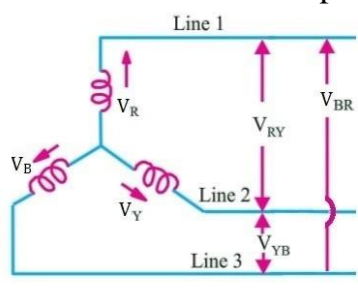

(a)

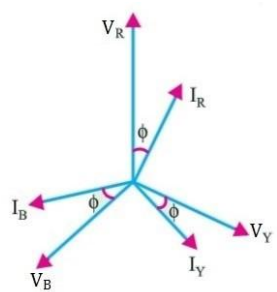

(b)
Figure 2: Voltage, Current and Power Values in Star (Y) Connection

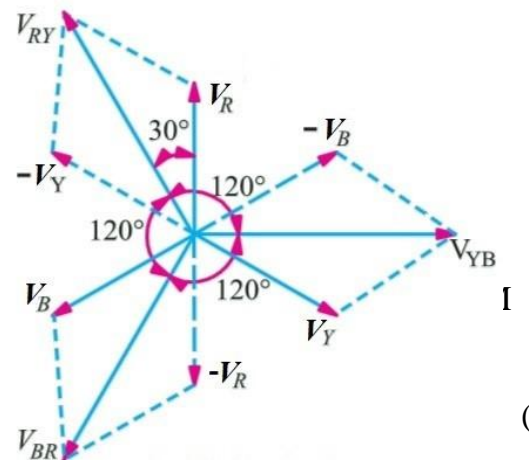

(4)

Figure 3: Line Voltages \& Phase Voltages in Star Connection

\section{Data Presentation, Discussions of the Results, Analysis}

Table 1: Day 1, Thursday $31^{\text {st }}$ March, 2016 


\section{International Journal of Science and Research (IJSR) \\ ISSN (Online): 2319-7064}

Index Copernicus Value (2013): 6.14 | Impact Factor (2015): 6.391

Clusters ie Current Per Phase (I ANCurrent/olatage Current Unbalance (\%) Power F PowerPower \begin{tabular}{|l|l|l|l|l|l|l|l}
\hline LRed. YellouL BlueNeutra Imax & (Volt) AVERAGI \%L1 & $\%$ L2 & $\%$ L3 & P.F & KVA & KW
\end{tabular}

\begin{tabular}{|l|l|l|l|l|l|l|l|l|l|l|l|l|}
\hline Cluster A 75 & 107 & 110 & 30 & 292 & 240 & 97.3 & $22.9 \%$ & $9.9 \%$ & $13.0 \%$ & 0.85 & 70.1 & 59.6 \\
\hline
\end{tabular}

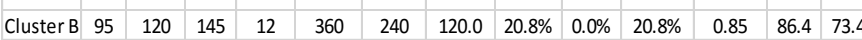

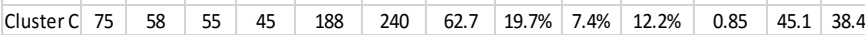

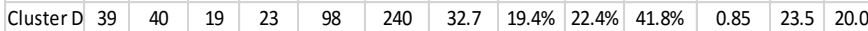
\begin{tabular}{|l|l|l|l|l|l|l|l|l|l|l|l|l|}
\hline Cluster E 174 & 98 & 0 & 95 & 272 & 240 & 90.7 & $91.9 \%$ & $8.1 \%$ & $100.0 \%$ & 0.85 & 65.3 & 55.5 \\
\hline
\end{tabular}

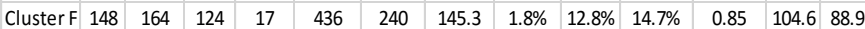

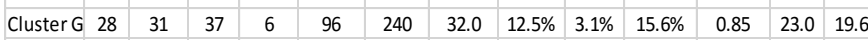

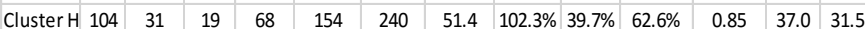

\section{Current Unbalance \% ( DAY 1)}

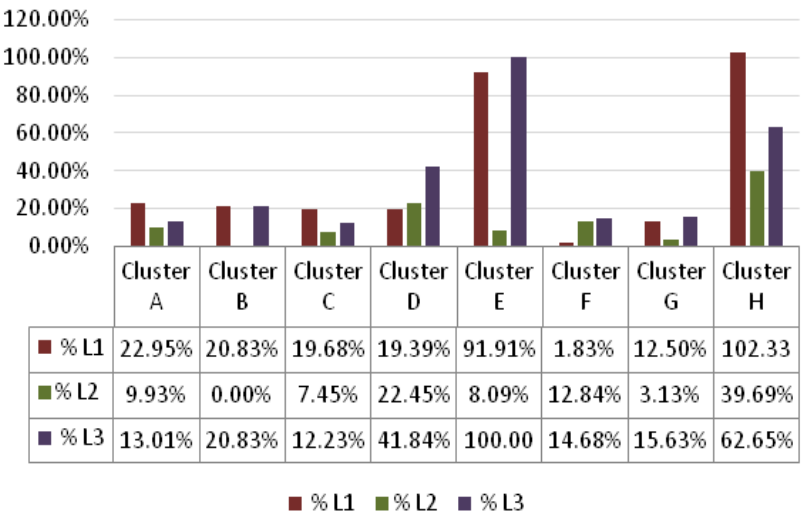

Figure 4:Current Unbalance Ratios for the Clusters on Day 1

6.1 Calculations to determination of $\mathrm{KW}$ and KVA in Table 1.0

Sample calculation based on Cluster G. of Table 1.0 Maximum Current $=$

$I_{\text {MAX }}=L_{1}+L_{2}+L_{a}=28+31+37=98 \mathrm{~A}$

- Phase voltage $=\mathrm{V}_{\mathrm{P}}=\frac{V_{L}}{\sqrt{3}}=\frac{415}{\sqrt{3}}=240 \mathrm{~V}$

Maximum Power Consumed $=I_{\max } \times$ $V_{p} \times \cos \emptyset=98 \times 240 \times 0.85=20 K W$

\section{- Maximum Power Supplied in KVA}

$$
=I_{\max } \times V_{p}=98 \times 240=23.5 \mathrm{KVA}
$$

For Cluster G,

$$
\text { average current }=L a v=\left(\frac{28+31+37}{3}\right)=
$$

\section{$32 \mathrm{~A}$}

Max deviation from average current $=$ $\mathrm{I}(37-32) \mid A=5 A$, using $L 3$

of Cluster G
Percentage Current Unbalance $=$

$\left(\frac{5}{32}\right) \times 100 \%=15.63 \%$

Current Rating of 500KVA Transformer

$$
=500 \mathrm{KVA} / 1.732 \times 415=695.62 \mathrm{~A}
$$

Current Rating of 315KVA Transformer

$$
=315 \mathrm{KVA} / 1.732 \times 415=438.24 \mathrm{~A}
$$

Total percentage load on transformer

$$
=\frac{\text { Elegs }}{\text { transformer rating }} \times 100 \%
$$

Total percentage load on transformer $=\frac{\sum L}{T R}$

$$
\begin{gathered}
\sum \text { oflegs }=\text { total sun of legs on transformer } \div 3 \\
=(292+360+188+98+154.2) \div 3=364.1 \mathrm{~A}
\end{gathered}
$$

Total percentage load on 500KVA transformer

$$
=\frac{364.1 \mathrm{~A}}{695.62 \mathrm{~A}} \times 100 \%=52.34 \%
$$

Total percentage load on transformer $=52.34 \%$ Similarly for 315KVA transformer, and using clusters (E, F, and $\mathrm{G})$ in Table 1.0

For 315 KVA Transformer

$\sum$ of legs $=(272+436+96) \div 3=$ $268 \mathrm{~A}$

Total percentage load on transformer

$$
=\frac{268 \mathrm{~A}}{438.24 \mathrm{~A}} \times 100 \%=61.10 \%
$$

Table 2: Day 2. Monday $4^{\text {th }}$ April, 2016

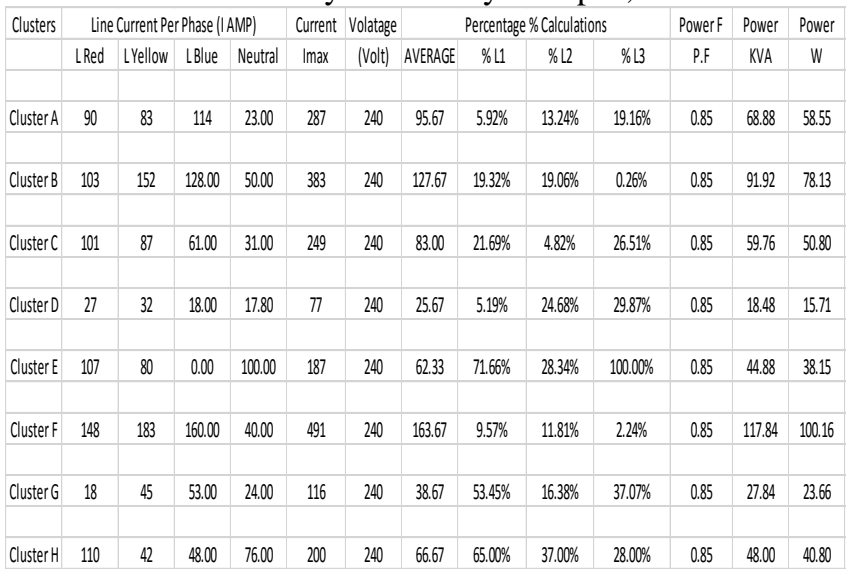

\section{Volume 5 Issue 6, June 2016} www.ijsr.net 


\section{International Journal of Science and Research (IJSR) \\ ISSN (Online): 2319-7064}

Index Copernicus Value (2013): 6.14 $\mid$ Impact Factor (2015): 6.391

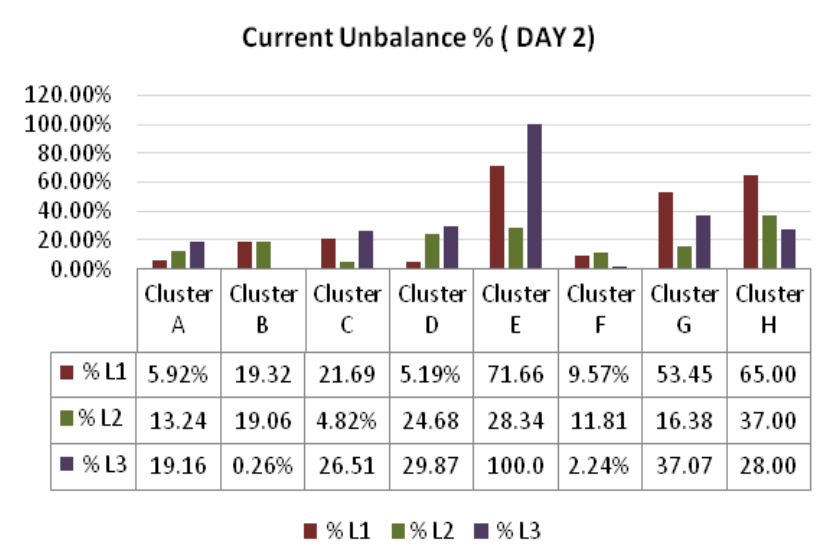

Figure 5: Current Unbalance Ratios for the Clusters on Day 2

- Total percentage load on transformer $=\frac{\text { Elegs }}{\text { transformer rating }} \times 100 \%$

- Total percentage load on transformer $=\frac{\text { Elegs }}{\text { trangformer rating }} \times 100 \%$

Total percentage load on transformer $=\frac{\sum L}{T R}$

$\sum$ of legs $=$

- total sum of legs on transformer $\div 3$

For 500 KVA Transformer

$\sum$ of legs $=(287+383+249+77+200) \div$

. $3=398.66 \mathrm{~A}$

- Total percentage load on 500 KVA transformer $=\frac{798.67}{695.62} \times 100 \%=57.31 \%$

For 315 KVA Transformer

- $\sum$ of legs $=(187+491+116) \div 3=264.67 \mathrm{~A}$

- Total percentage load on 315KVA transformer = $\frac{264.67 \mathrm{~A}}{438.24 \mathrm{~A}} \times 100 \%=60.39 \%$

Table 3: Day 3. Tuesday $5^{\text {th }}$ April 2016

Cluster Line Current Per Phase (IAMP) Current Volatage Percentage Unbalanced PowerF Power Power \begin{tabular}{|l|l|l|l|l|l|l|l|l|l|}
\hline LRed LYellow LBlue Neutral Imax & (Volt) & AVERAGE & $\%$ L1 & $\%$ L2 & $\%$ L3 & P.F & KVA & KW
\end{tabular}

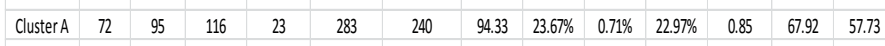

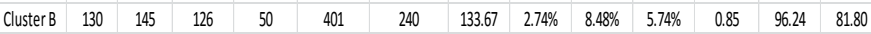

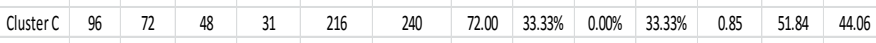

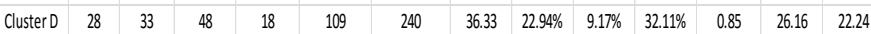

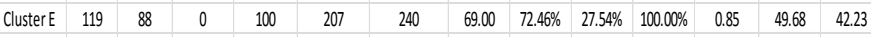

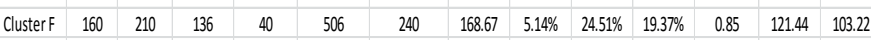

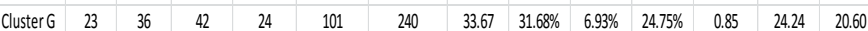

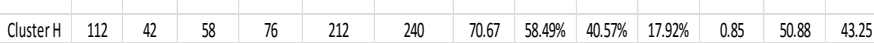

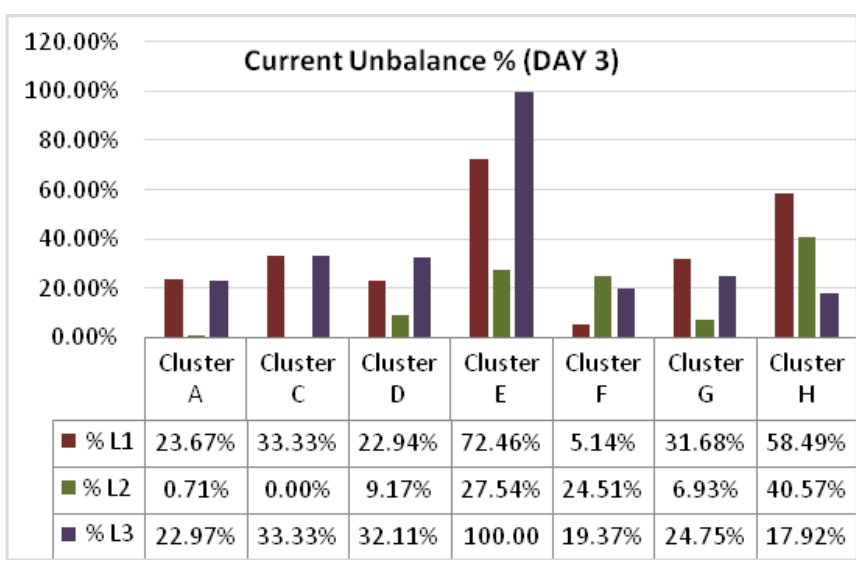

Figure 6: Current Unbalance Ratios for the Clusters on Day 3

For 500 KVA Transformer

$\sum$ of legs $=(283+401+216+109+212) \div$ - $3=407 \mathrm{~A}$

- Total percentage load on 500 KVA transformer $=\frac{407}{695.62} \times 100 \%=58.51 \%$

For 315 KVA Transformer

- $\sum$ of legs $=(207+506+101) \div 3=271.33 \mathrm{~A}$

- Total percentage load on $315 \mathrm{KVA}$ transformer $=$ $\frac{271.29 \mathrm{~A}}{438.24 \mathrm{~A}} \times 100 \%=61.91 \%$

Table 4: Neutral Current in Amperes measured for the clusters during the 3 days

\begin{tabular}{|l|c|c|l|l|}
\hline Cluster & DAY 1 & DAY2 & DAY3 & Ave. IN \\
\hline \multicolumn{4}{|c|}{ NEUTRAL CURRANTS (A) } \\
\hline Cluster A & 30.00 & 23.00 & 33 & 29 \\
\hline Cluster B & 12.00 & 50.00 & 17.00 & 26 \\
\hline Cluster C & 45.00 & 31.00 & 40.00 & 39 \\
\hline Cluster D & 23.00 & 17.80 & 14.00 & 18 \\
\hline Cluster E & 95.00 & 100.00 & 96.00 & 97 \\
\hline Cluster F & 17.00 & 40.00 & 32.00 & 30 \\
\hline Cluster G & 6.00 & 24.00 & 11.00 & 14 \\
\hline Cluster H & 68.00 & 76.00 & 60.00 & 68 \\
\hline
\end{tabular}

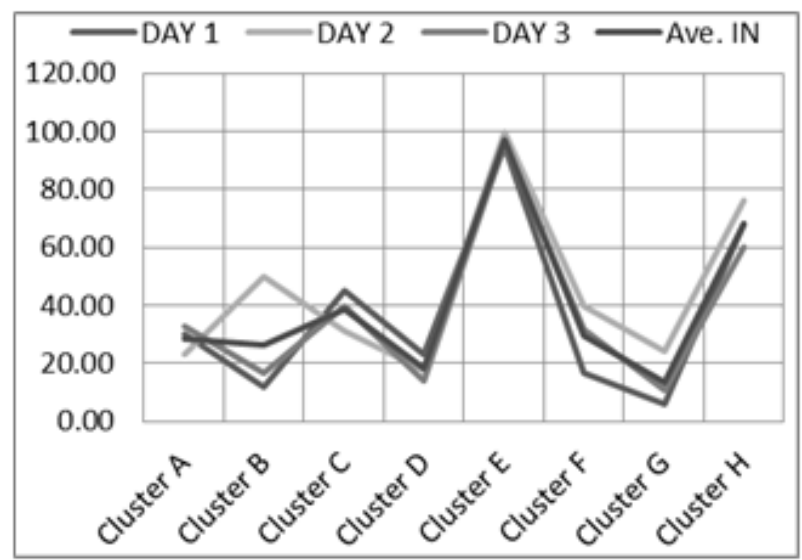

Figure 7: The relationship between Average neutral current (Ave IN) in Amperes measured for each cluster during the period under Test.

\section{Volume 5 Issue 6, June 2016} www.ijsr.net 


\section{International Journal of Science and Research (IJSR) \\ ISSN (Online): 2319-7064 \\ Index Copernicus Value (2013): 6.14 | Impact Factor (2015): 6.391}

Figure 8.0 is the picture of the clamp-on multi-meter used for collecting the quantities in the research.

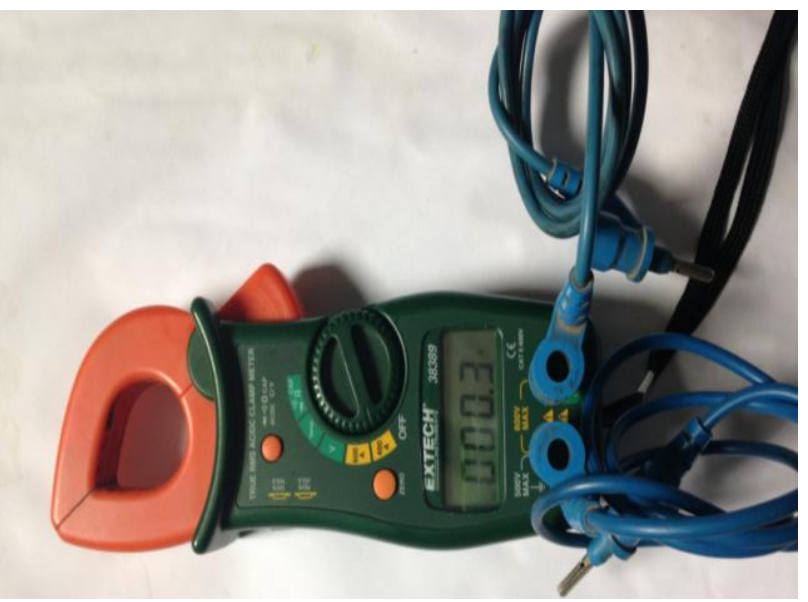

Figure 8: Clamp-on-multi-meter used for the study

Table 5: Average Values of Maximum Power Consumed (KW) and Maximum Power Supplied (KVA) from Tables $1.0,2.0,3.0$

\begin{tabular}{|c|c|c|c|c|c|c|}
\hline \multirow[t]{2}{*}{ Cluster } & \multicolumn{3}{|c|}{ TOTAL CLUSTER CURRENT (A } & \multirow{2}{*}{$\begin{array}{c}\text { A VE. VALUE OF } \\
\text { TOTALCURRENT (A) }\end{array}$} & \multicolumn{2}{|c|}{ AVE. VALUE } \\
\hline & DAY 1 & DAY 2 & DAY 3 & & KVA & $\mathrm{KW}$ \\
\hline Cluster A & 292 & 287 & 287 & 288.7 & 69.3 & 58.9 \\
\hline Cluster B & 360 & 383 & 383 & 375.3 & 90.1 & 76.6 \\
\hline Cluster C & 188 & 249 & 249 & 228.7 & 54.9 & 46.6 \\
\hline Cluster D & 98 & 77 & 77 & 84.0 & 20.2 & 17.1 \\
\hline Cluster E & 272 & 187 & 187 & 215.3 & 51.7 & 43.9 \\
\hline Cluster F & 436 & 491 & 491 & 472.7 & 113.4 & 96.4 \\
\hline Cluster G & 96 & 116 & 116 & 109.3 & 26.2 & 22.3 \\
\hline Cluster H & 154 & 200 & 200 & 184.7 & 44.3 & 37.7 \\
\hline
\end{tabular}

\section{Average Values of KVA and} KW

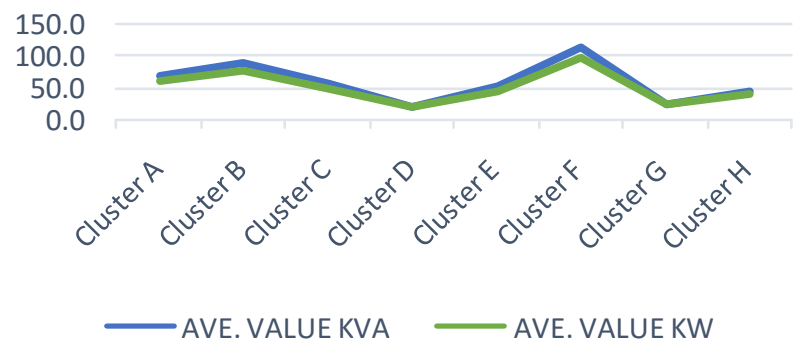

Figure 9: Average Values of Maximum Power Consumed $(\mathrm{KW})$ and Maximum Power Supplied (KVA) of the Clusters

\subsection{Calculations in Table 1}

Average power monitored for the three days $=\frac{\text { Total load }}{a}$

Average total current recorded Cluster A, $\frac{866}{a}=288.7 \mathrm{~A}$

Maximum power $=P_{\text {MAX }}=I_{\text {MAX }} \times V_{p} \times \operatorname{Cos} \varphi$
$P_{\text {MAX }}=288.66 \times 240 \times 0.85=58.9 \mathrm{KW}$ as indicated in Table 5.0

Power in KVA $=I_{\text {MAX }} \times V_{p}=288.7 \times 240=69.3 \mathrm{KVA}$ as indicated in Table 5.0

The total average KVA for the 500KVA Transformer, from Table 5.0 (Clusters A, B, C, D, H) is $278.8 \mathrm{KVA}$ and for $315 \mathrm{KVA}$ Clusters $(\mathrm{E}, \mathrm{F}, \mathrm{G})$ it also recorded 191.3KVA.

Total Capacity power plant of the institution and its immediate community $=815 \mathrm{KVA}$ made up of;

- 500KVA

- $315 \mathrm{KVA}$

Computing for the 500KVA transformer, the \% of the existing load over installed capacity

$=\frac{\text { existing }}{\text { install }} \times 100 \%=\frac{278.8 \mathrm{KVA}}{500 \mathrm{KVA}} \times 100 \%=55.76 \%$

Computing for the 315KVA transformer, the $\%$ of the existing load over the installed capacity

$=\frac{\text { existing }}{\text { install }} \times 100 \%=\frac{191.3 \mathrm{KVA}}{315 \mathrm{KVA}} \times 100 \%=60.73 \%$

\subsection{Discussions}

Observation and comments are made under the following three main areas.

- Transformer

- The Distribution System

- Safety

\section{Transformer}

A transformer is a very paramount component in power distribution system. For continuous reliable power, proper safety measures should be put in place to ensure safety of the environment. Copper losses (winding resistance), Core or Iron losses and Leakage flux or mechanical losses. The total imbalance in the system is alarming and require immediate rectification. Computer loads create high harmonic distortion. In an institution with a lot of computers and printers being used in all offices and laboratories, the r.m.s neutral current can exceed the r.m.s phase current due to the presence of zero sequence harmonic [1].

\section{The Distribution System}

The results in Table 1.0. 2.0 and 3.0 indicated that one of the phases in cluster E, the Blue phase is damaged and required prompt attention.

Safety

The total loads connected on transformer (A) 500KVA and (B) $315 \mathrm{KVA}$ is in good condition. However Unbalanced Phases with vast differences in phase currents if not checked can lead to fire outbreak.

\section{Recommendations}

After going through the exercise, the following recommendations are suggested:

\section{Volume 5 Issue 6, June 2016 www.ijsr.net}




\section{International Journal of Science and Research (IJSR) \\ ISSN (Online): 2319-7064}

Index Copernicus Value (2013): 6.14 | Impact Factor (2015): 6.391

Measures need to be put in place to reduce the high percentage current unbalance and its associated high neutral current. Elimination of shared neutrals in branch circuits wherever possible.

Size of neutral wire in three phase wye panel, can be increased so it won't over heat, due to excess neutral current. There should be proper isolation between clusters to prevent faulty clusters from affecting the overall system.

The Earthing system in the institution must be adequately assessed, to determine its effectiveness, since it has a major influence on the energy consumption.

Proper testing and communication with the utility company would help locate and resolve most of the problems.

\section{Conclusion}

The high unbalanced phases in the system, has resulted in high values of neutral currents in system. The average value of neutral current within each cluster is very high. Increase in neutral currents leads to increase in $\mathrm{I}^{2} \mathrm{R}$ losses, and a decrease in the transformer efficiency. Current unbalance can be caused by large and or unequal distribution of single-phase load, phase to phase loads and unbalanced three phase loads. Unbalanced phases can lead to intermittent failure of breakers and fire outbreaks. Percentage current Unbalance in each cluster has highly exceeded $10 \%$ of acceptable limit. Percentage Current unbalance of $100 \%$ is recorded for cluster E. Current unbalance produces heat in motor windings that degrades motor insulation causing cumulative and permanent damage to the motor. Restoring the damaged phase on cluster E will greatly reduce the high percentage current Unbalance. Unresolved damaged phase in cluster E, can lead to unnecessary overloading on the system leading to fire outbreak and phase sequence fault. Total percentage load on the 500KVA transformer is in the range of $52 \%$ to $58.5 \%$, and that for the $315 \mathrm{KVA}$ transformer $60 \%$ to $62 \%$.

\section{Acknowledgement}

Our thanks to the Management of the Kumasi Polytechnic for providing necessary facilities to carry out this work.

\section{Reference}

[1] Dey, N., \& Chakraborty, A. K. (2013). Neutral Current and Neutral Voltage in Three Phase Four Wire Distribution System of a Technical Institution. International Journal of Computer Applications, 72(3).

[2] Arthur, R., \& Shanahan, R. A. (1996, August). Neutral currents in three phase wye systems. In IEEE, 7 th. International Conference on Harmonics and Quality of Power. Las Vegas, USA (Vol. 16).

[3] Energy Commission of Ghana -LI 1816 (2005). Electricity Supply and Distribution (Technical and Operational) Rules.

[4] Theraja, B. L., \& Theraja, A. K. (2007). A Textbook of Electrical Technology: Basic Electrical Engineering in SI
Unitsll, vol. 1. S. Chand Publications. pp 665-752, pp $115-1210$

[5] Hughes, E., Hiley, J., Brown, K., \& Smith, I. M. (2008). Hughes electrical and electronic technology. Pearson education.

[6] Ali Hasanbeigi, Lynn Price (2010). Industrial Energy Audit Guidebook: Guidelines for conducting an Energy Audit in Industrial Facilities. October 2010.

[7] Maheswaran, D., Kalyanasundaram, A., \& Kameshwaran, S. (2006, December). Power quality issues in a distribution network impact of neutral current due to nonlinear loads. In 2006 India International Conference on Power Electronics.

[8] Zeifman, M., Akers, C., \& Roth, K. (2011). Nonintrusive Appliance Load Monitoring (NIALM) for Energy Control in Residential Buildings: Review and Outlook. In IEEE transactions on Consumer Electronics.

[9] Michael Zeifman, Kurt Roth. (2012), Non-Intrusive Appliance Load Monitoring (NIALM): Promise and Practice.

\section{Author Profile}

Ing. Kwadwo Ntiamoah-Sarpong (MGhIE) received the BSc. in Electrical \& Electronic Engineering from the Kwame Nkrumah University of Science and Technology in 2005 and MSc. degree in Telecommunication Management from Han University of Applied Science and TUDelft in 2011. From 2011 till now, he has been a Lecturer in the Dept. of Electrical and Electronic Engineering, Kumasi Polytechnic. He teaches courses such as Network Analysis, Digital Electronics, Engineering Practice and Maintenance, and Communication Systems He has also untaken teaching jobs as a part-time lecturer at The Ghana Technology University College teaching courses such as Engineer and Society, Sociology of Technology and Electronic Communication. He is a member of the Ghana Institution of Engineers (GhIE).

Mr. Kwame Sarfo is a Lecturer at the Faculty of Engineering, Kumasi Polytechnic. He teaches Power Systems and Electronics. $\mathrm{He}$ obtained his BSc. In Electrical Engineering from the Kwame Nkrumah University of Science and Technology. He also possess an MSc. In Telecommunication Management from the Han University of Applied Sciences. His area of specilisation is in the transmission and distribution of Electrical Power.

Mr. Johannex Fefeh. Rushman, is a Lecturer at the Faculty of Engineering, Kumasi Polytechnic. He obtained his MTech. In Electrical \& Electronic Engineering from the University of Education, Winneba. His area of specialisation is in Electrical Machines and Fault Diagnosis of Electrical Systems. His current area of interest is in Renewable Energy.

Mrs Achiaa Donkor is a Lecturer at the Faculty of Engineering, Kumasi Polytechnic. She teaches Telecommunications and Digital Electronics. She obtained her BSc. in Physics and MSc. in Telecommunications Engineering, from the Kwame Nkrumah University of Science and Technology, Kumasi. Her area of specialisation is in the Telecommunication Transmission and Data Access and Microwaves in Telecommunication. 